\title{
INDENTIFIKASI SWAMEDIKASI PENGEMUDI ANGKUTAN UMUM DI KECAMATAN PARONGPONG KABUPATEN BANDUNG BARAT
}

\author{
Identification of Public Transport Drivers' Self-medication in Parongpong \\ District Bandung Barat District
}

\author{
Cindy Herliani Setiawan ${ }^{1}$, Untung Sudharmono ${ }^{2}$ \\ Fakultas Ilmu Keperawatan Universitas Advent Indonesia ${ }^{1,2}$ \\ Email : cindysetiawan40@gmail.com
}

\begin{abstract}
ABSTRAK
Pendahuluan: Swamedikasi adalah pemilihan obat-obatan untuk mengobati gejala dan gangguan pada diri sendiri tanpa menggunakan resep dokter. Pelaku swamedikasi datang dari berbagai kalangan, termasuk para pengemudi angkutan umum. Dan jika swamedikasi di lakukan tidak tepat maka akan memboroskan biaya, waktu, bahkan akan timbul gejala yang tidak diinginkan, karena adanya efek samping dalam obat yang digunakan. Tujuan : Tujuan pada penelitian ini mengidentifikasi swamedikasi pengemudi angkutan umum di terminal Parongpong Kabupaten Bandung Barat. Metode: Metode penelitian ini deskriptif kuantitatif. Sampel dalam penelitian ini diambil dengan cara purposive sampling dengan 126 responden yang berprofesi sebagai pengemudi angkutan umum. Hasil : Hasil dari penelitian ini didapatkan bahwa $66 \%$ responden melakukan swamedikasi dan $34 \%$ responden tidak melakukan swamedikasi. Semua jenis obat yang digunakan banyak ditemukan bebas di warung, toko obat dan apotek dan memiliki efek samping yang dapat menyebabkan penurunan konsentrasi pengemudi dan dapat menimbulkan kecelakaan lalu lintas yang dapat merugikan diri sendiri bahkan orang di sekitar. Diskusi: Oleh sebab itu, disarankan kepada para pelaku swamedikasi terutama pengemudi angkutan umum agar tidak terlalu sering mengkonsumsi obat-obatan tanpa resep dokter.
\end{abstract}

Kata kunci: Efek samping, Pengemudi angkutan umum, Swamedikasi,

\begin{abstract}
Introduction: Self-medication is the selection of medicines to treat symptoms and disorders of yourself without using a doctor's prescription. The perpetrators of self-medication came from various circles, including public transportation drivers. And if self-medication is done inappropriately, it will be a waste of money, time, and even symptoms will arise that are not desirable, because of the side effects in the drugs used. purpose: The purpose of this study is to identify self-transportation of public transport drivers in the Parongpong terminal, West Bandung Regency. Method: This research method is quantitative descriptive. The sample in this study was taken by purposive sampling with 126 respondents who work as public transportation drivers. . Results: The results of this study found that $66 \%$ of respondents did self-medication and $34 \%$ of respondents did not do self-medication. All types of drugs used are found to be free in stalls, drug stores and pharmacies and have side effects that can cause a decrease in the concentration of the driver and can cause traffic accidents that can be detrimental to oneself even people around. Discussion: Therefore, it is suggested to the perpetrators of self-medication especially public transportation drivers not to consume drugs too often without a doctor's prescription.
\end{abstract}

JURNAL

SKOLASTIK

KEPERAWATAN

Vol, 5, No. 2

Juli - Desember 2019

ISSN: $2443-0935$

E-ISSN 2443 - 16990 
Keywords: Public transport drivers, Self-medication, Side effects,

\section{PENDAHULUAN}

Kesehatan adalah harta yang paling berharga, sehingga seseorang akan melakukan sesuatu kepada dirinya jika merasakan gejala dan gangguan pada tubuhnya. Menurut WHO, swamedikasi adalah pemilihan obatobatan untuk mengobati gejala dan gangguan pada diri sendiri tanpa menggunakan resep dokter. ${ }^{1}$

Gejala dan gangguan seperti batuk; flu, demam, pusing, diare merupakan alasan individu melakukan swamedikasi dengan membeli obatobatan di warung tanpa resep dokter. ${ }^{2}$

Pelaku swamedikasi datang dari berbagai kalangan, termasuk para pengemudi angkutan umum. Terdapat $82.0 \%$ masyarakat Indonesia yang melakukan pengobatan sendiri atau swamedikasi menurut data dari laporan Kementrian Kesehatan Republik Indonesia tahun 2013. ${ }^{3}$ Sisanya mencari pengobatan antara lain ke puskesmas, paramedis, dokter praktik, rumah sakit, balai pengobatan, dan pengobatan tradisional. ${ }^{4}$

Pemilihan pengobatan sendiri di dorong oleh beberapa faktor, diantaranya penyakit yang di derita tidak terlalu parah, sebagai upaya pertolongan pertama, taraf ekonomi keluarga yang rendah, pendidikan rendah dan pengalaman terhadap penyakit yang diderita. $^{5}$

Keuntungan swamedikasi, jika dilakukan dengan tepat dan benar maka akan menghemat biaya, waktu dan efektif dalam menghilangkan keluhan pada gejala yang dialami. Namun sebaliknya, jika swamedikasi di lakukan tidak tepat maka akan memboroskan biaya, waktu, bahkan akan timbul gejala yang tidak diinginkan, karena adanya efek samping dalam obat yang digunakan. ${ }^{6}$

\section{TUJUAN PENELITIAN}

Tujuan pada penelitian ini mengidentifikasi swamedikasi pengemudi angkutan umum di terminal Parongpong Kabupaten Bandung Barat. Manfaat hasil dari penelitian ini diharapkan menambahkan informasi bagi petugas kesehatan dalam mengidentifikasi resiko yang mungkin terjadi akibat dari efek samping swamedikasi dari para pengemudi angkutan umum. Bagi para pengemudi angkutan umum yang menjadi subjek penelitian ini dapat menambahkan informasi dan pengetahuan mereka saat akan melakukan swamedikasi.

\section{METODE}

Metode penelitian ini menggunakan metode penelitian deskriptif kuantitatif. Menurut Sudarwan (2003), penelitian deskriptif kuantitatif adalah penelitian yang di maksudkan untuk menjelaskan suatu keadaan yang bersifat faktual secara sistematis dan akurat. ${ }^{7}$

Menurut hasil interview peneliti dengan kepala terminal parongpong jumlah pengemudi angkutan umum di terminal parongpong dengan 5 trayek angkutan berjumlah 340 pengemudi dan yang aktif hanya berjumlah 177 pengemudi. Sampel dalam penelitian ini diambil 
dengan cara purposive sampling. Menurut Dempsey (2002) bahwa purposive sampling adalah teknik pengambilan sampel yang dianggap representatif dari populasi dan dengan sengaja memilih unit sampling yang sesuai dengan konteks penelitian. ${ }^{8}$ Sampel penelitian ini adalah pengemudi angkutan umum yang berjumlah 126 responden yang ditemui oleh peneliti pada saat penelitian berlangsung di terminal Kecamatan Parongpong Kabupaten Bandung Barat.

Instrumen disusun oleh peneliti sendiri yang berjumlah 10 pertanyaan yang digunakan untuk memandu wawancara dalam penelitian ini.

\section{HASIL DAN PEMBAHASAN}

Berdasarkan hasil wawancara yang telah dilakukan dengan pengemudi angkutan umum di terminal Parongpong didapatkan bahwa 66\% responden melakukan swamedikasi dan $34 \%$ responden tidak melakukan swamedikasi. Semua jenis obat yang digunakan banyak ditemukan bebas di warung, toko obat dan apotek.

Obat yang banyak digunakan adalah antipiretik, antasida, antidiare, antialergi, antitusif, antiinfluenza, mukolitik \& ekspektoran dan analgesic non narkotika.

Tabel 1. Persentase jenis obat swamedikasi pengemudi angkutan umum

\begin{tabular}{cccc}
\hline $\mathrm{N}$ & Obat & $\begin{array}{c}\text { Jumlah } \\
\text { Penggun } \\
\mathrm{a}\end{array}$ & $\begin{array}{c}\text { Persentas } \\
\mathrm{e}\end{array}$ \\
\hline 1 & Lambung & 42 & $51 \%$ \\
\hline
\end{tabular}

\begin{tabular}{lccc}
\hline & Batuk & & \\
2 & pilek & 64 & $77 \%$ \\
3 & Analgesic & 80 & $96 \%$ \\
& darah & & \\
4 & tinggi & 13 & $16 \%$ \\
5 & gula darah & 0 & $0 \%$ \\
6 & Antibiotic & 2 & $2 \%$ \\
7 & Vitamin & 2 & $2 \%$ \\
8 & Alergi & 17 & $20 \%$ \\
9 & Diare & 28 & $34 \%$ \\
\hline
\end{tabular}

Berdasarkan data dari tabel 1. Menunjukkan persentase jenis obat swamedikasi pengemudi angkutan umum yaitu analgesic berada di posisi tertinggi dengan persentase $96 \%$ dari jumlah 83 responden yang swamedikasi, diikuti obat batuk pilek dengan persentase $77 \%$ dan obat lambung dengan persentase $51 \%$.

Tabel 2. Persentase kandungan obat lambung swamedikasi pengemudi angkutan umum

\begin{tabular}{|c|c|c|c|}
\hline $\begin{array}{l}\mathrm{N} \\
\mathrm{O}\end{array}$ & $\begin{array}{c}\text { Kandungan } \\
\text { Obat }\end{array}$ & $\begin{array}{c}\text { Jumlah } \\
\text { Penggu } \\
\text { na }\end{array}$ & $\begin{array}{c}\text { Persenta } \\
\text { se }\end{array}$ \\
\hline 1 & $\begin{array}{l}\text { Hidrotalcite, } \\
\text { magnesium } \\
\text { hydroxide, } \\
\text { simethicone }\end{array}$ & 31 & $74 \%$ \\
\hline 2 & $\begin{array}{l}\text { Al-hidroksida } \\
\text { gel, mg- } \\
\text { hidroksida, } \\
\text { simetikon }\end{array}$ & 7 & $17 \%$ \\
\hline 3 & $\begin{array}{l}\text { Dimetilpolisilok } \\
\text { san, al- } \\
\text { hidroksida, mg- } \\
\text { hidroksida }\end{array}$ & 2 & $5 \%$ \\
\hline 5 & Ranitidine & 2 & $5 \%$ \\
\hline
\end{tabular}

Berdasarkan data dari tabel 2. Menujukkan persentase kandungan obat lambung swamedikasi pengemudi angkutan yaitu kandungan hidrotalcite, magnesium hydroxide, simethicone 
dengan persentase tertinggi $74 \%$, iikuti oleh kandungan al-hidroksida gel, mghidroksida, simetikon dengan persentase $17 \%$.

Kandungan obat-obatan diatas memiliki efek samping jika digunakan secara berkepanjangan dan tanpa resep dokter.

Kandungan ranitidine mengakibatkan efek samping sakit kepala, tidak enak badan, mengantuk, insomnia, vertigo, dan pada dosis berlebih akan mengakibatkan halusinasi, aritmia, takikardia, perubahan hematologi, gangguan endokrin, gangguan gastrointestinal dan kelainan kulit. ${ }^{11}$ Kandungan hidrotalcite, magnesium hydroxide, simethicone memiliki efek samping sembelit, diare, mual dan muntah. ${ }^{10}$

Tabel 3. Persentase kandungan obat batuk/pilek swamedikasi pengemudi angkutan umum

\begin{tabular}{cccc}
\hline No & $\begin{array}{c}\text { Kandungan } \\
\text { Obat }\end{array}$ & $\begin{array}{c}\text { Jumlah } \\
\text { Penggun } \\
\text { a }\end{array}$ & $\begin{array}{c}\text { Persent } \\
\text { ase }\end{array}$ \\
\hline Dekstrometorf \\
an HBr, \\
gliserilgualako \\
lat, \\
difenhidramin \\
HCL \\
Dextromethor \\
phan HBr, \\
doxylamine \\
succinate \\
Guaifenesin, \\
dextromethorp \\
han HBr, \\
chlorpheniram \\
ine maleate \\
Paracetamol, \\
pseudoefedrin \\
HCL,
\end{tabular}

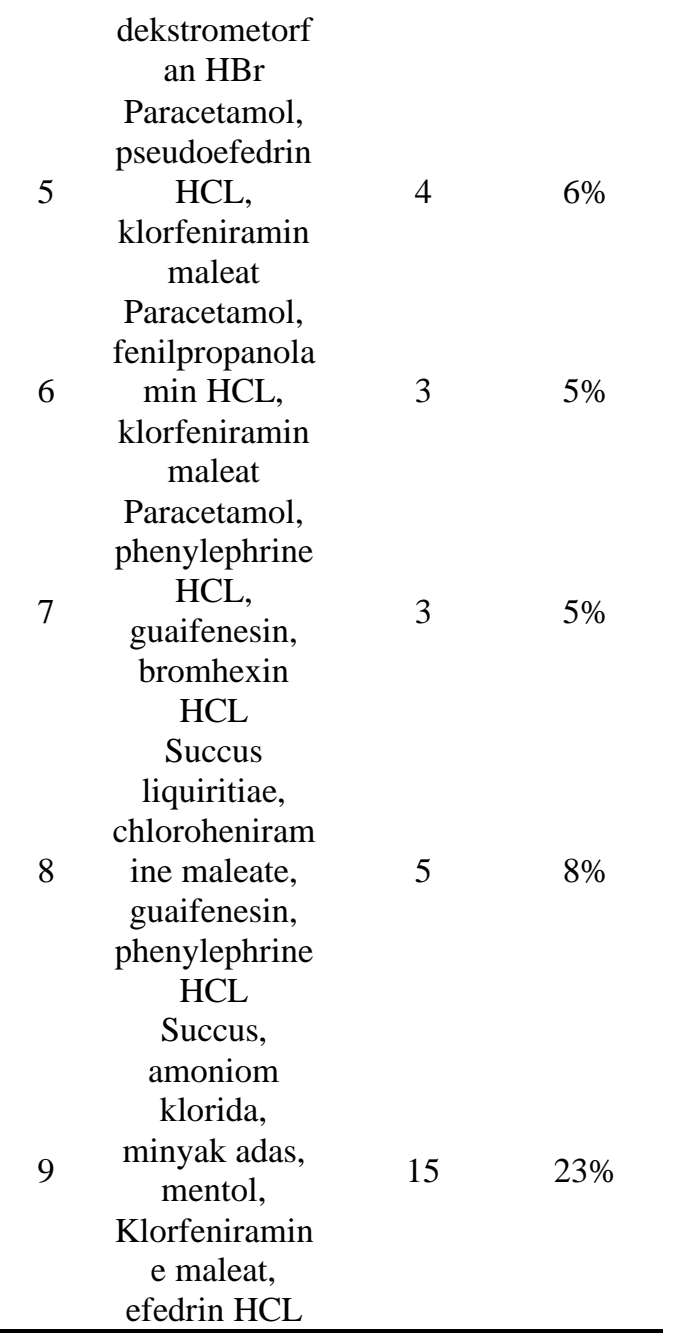

Berdasarkan data dari tabel 3. Menunjukkan persentase kandungan obat batuk/pilek swamedikasi pengemudi angkutan yaitu kandungan succus, amoniom klorida, minyak adas, mentol, Klorfeniramine maleat, efedrin HCL berada di posisi tertinggi dengan persentase $23 \%$, diikuti oleh kandungan paracetamol, pseudoefedrin HCL, dekstrometorfan $\mathrm{HBr}$ dengan persentase $17 \%$ dan kandungan guaifenesin, dextromethorphan $\mathrm{HBr}$, chlorpheniramine maleate dengan persentase $16 \%$. 
Dari tabel diatas kandungan obat-obat tersebut dapat memiliki efek samping yang akan berpengaruh terhadap pengemudi angkutan umum jika dikonsumsi secara terus menerus.

Kandungan dekstrometorfan $\mathrm{HBr}$ memiliki efek samping berkeringat, bicara kacau, kelelahan, dan depresi sistem pernapasan jika digunakan dalam dosis yang berlebih akan memberikan efek halusinasi penglihatan dan pendengaran, euphoria dan rasa tenang. ${ }^{14}$ Kandungan Guaifenesin mengakibatkan efek samping mengantuk dan mual. Kandungan chlorpheniramine maleate memiliki efek samping mulut kering dan mengantuk bahkan pada dosis berlebihan akan mengakibatkan pandangan kabur.

Kandungan pseudoefedrin HCL akan berakibat insomnia, sakit kepala, sulit buang air besar, dan pada dosis besar akan berakibat takikaridia, tremor, palpitasi dan aritmia. Kandungan bromhexin HCL memiliki efek samping mual, muntah, rasa penuh di perut, sakit kepala dan berkeringat pada malam hari. ${ }^{10}$

Tabel 4. Persentase kandungan obat analgesic swamedikasi pengemudi angkutan

\begin{tabular}{|c|c|c|c|}
\hline No & Kandungan Obat & $\begin{array}{c}\text { Jumlah } \\
\text { Pengguna } \\
\end{array}$ & Persentase \\
\hline 1 & Paracetamol & 32 & $40 \%$ \\
\hline 2 & Metampiron & 2 & $3 \%$ \\
\hline 3 & asam mefenamat & 7 & $9 \%$ \\
\hline 4 & $\begin{array}{l}\text { Ibuprofen, } \\
\text { paracetamol }\end{array}$ & 3 & $4 \%$ \\
\hline 5 & $\begin{array}{l}\text { Paracetamol, } \\
\text { ibuprofen, caffeine }\end{array}$ & 10 & $13 \%$ \\
\hline 6 & $\begin{array}{l}\text { Propifenazon, } \\
\text { paracetamol, } \\
\text { deksklorfemiramin } \\
\text { maleat, kafein } \\
\text { anhidrat }\end{array}$ & 16 & $20 \%$ \\
\hline 7 & $\begin{array}{l}\text { Paracetamol, } \\
\text { kafein }\end{array}$ & 7 & $9 \%$ \\
\hline 8 & $\begin{array}{l}\text { Paracetamol, } \\
\text { acetosal, caffeine }\end{array}$ & 3 & $4 \%$ \\
\hline
\end{tabular}

Berdasarkan data dari tabel 4 . Menunjukkan persentase kandungan obat analgesic swamedikasi pengemudi angkutan yaitu kandungan paracetamol dengan persentase tertinggi dengan persentase $40 \%$, diikuti oleh kandungan propifenazon, paracetamol, deksklorfemiramin maleat, kafein anhidrat dengan persentase $16 \%$ dan kandungan paracetamol, ibuprofen, caffeine dengan persentase $10 \%$.

Kandungan obat-obat yang sering dikonsumsi tersebut memiliki efek samping yang akan berakibat terutama dalam profesi pengemudi angkutan umum.

Kandungan paracetamol memiliki efek samping reaksi alergi pada kulit, reaksi hipersensitivitas, dan peningkatan kadar enzim hati. ${ }^{9}$ Kandung obat Metampiron berefek samping terhadap agranulositosis dan reaksi hipersensitivitas. ${ }^{10}$ Kandungan asam mefenamat memiliki efek samping mengantuk, diare, gelisah, dan hipotensi. $^{11}$ 
Kandungan ibuprofen memiliki efek samping gangguan pencernaan seperti mual dan muntah, ruam pada kulit dan pada keadaan berat dapat terjadi penurunan ketajaman penglihatan. ${ }^{9}$ Mengkonsumsi kafein dengan dosis yang berlebihan memiliki efek samping kejang insomnia, nyeri kepala, hipertensi, tremor, gugup dan gelisah dan mual bahkan muntah. 12 Kandungan deksklorfemiramin maleat memiliki efek samping mengantuk, dan pada dosis yang besar dapat beakibat terhadap gangguan kardiovaskular, hematologi, neuorologi, respirasi, gastrointestinal, dan genitourinary. ${ }^{10}$ Kandungan asetosal dapat berefek pada iritasi lambung karena asetosal bereaksi asam. $^{13}$

Tabel 5. Persentase kandungan obat diare swamedikasi pengemudi angkutan umum

\begin{tabular}{|c|c|c|c|}
\hline No & $\begin{array}{l}\text { Kandungan } \\
\text { Obat }\end{array}$ & $\begin{array}{c}\text { Jumlah } \\
\text { Pengguna }\end{array}$ & Persentase \\
\hline 1 & $\begin{array}{l}\text { Daun jambu } \\
\text { biji, kunyit, } \\
\text { buah } \\
\text { mojokeling, } \\
\text { buah delima }\end{array}$ & 19 & $68 \%$ \\
\hline 2 & $\begin{array}{l}\text { Attapulgite } \\
\text { aktif }\end{array}$ & 8 & $29 \%$ \\
\hline 3 & Furazolidone & 1 & $4 \%$ \\
\hline \multicolumn{4}{|c|}{$\begin{array}{l}\text { Berdasarkan data dari tabel } 5 \text {. } \\
\text { Menunjukkan persentase kandungan } \\
\text { obat diare swamedikasi pengemudi } \\
\text { angkutan yaitu kandungan daun jambu } \\
\text { biji, kunyit, buah mojokeling, buah } \\
\text { delima dengan persetase teritinggi } 68 \% \\
\text { dan diikuti oleh antapulgit aktif dengan } \\
\text { persentase } 29 \% \text {. }\end{array}$} \\
\hline
\end{tabular}

Menurut data dari tabel diatas beberapa kandungan yang dikonsumsi secara swamedikasi oleh pengemudi memiliki efek samping yang dapat merugikan bahkan dapat memperparah penyakit. Kandungan attapulgite aktif memiliki efek samping konstipasi ringan atau sembelit. ${ }^{10}$

Selain dari tabel diatas ada juga beberapa kandungan obat yang dikonsumsi dan di beli bebas oleh pengemudi angkutan umum yaitu kandungan amlodipine besylate yang memiliki efek samping pusing, sakit kepala, kemerahan, mengantuk, mual, dan pada keadaan parah samnolen, edema perifer dan palpitasi. ${ }^{11}$

Kandungan lain yang juga di konsumsi bebas oleh pengemudi angkutan umum adalah amoxicillin yang termasuk kedalam golongan obat keras. Obat keras adalah obat yang harus menggunakan resep dokter untuk mendapatkannya karena berkhasiat keras dan dapat meracuni tubuh, memperparah penyakit bahkan dapat menyebabkan kematian. ${ }^{15}$ Sedangkan efek samping dari kandungan amoxicillin adalah mual, muntah, reaksi alergi, anafilaksis, gangguaun hematologi dan gangguan gastrointestinal. ${ }^{11}$

Jenis obat antialergi banyak juga dikonsumsi bebas oleh pengemudi angkutan umum, jenis obat antialergi mengandung klorfeniramine maleat yang mempunyai efek samping pusing, mengantuk, gangguan koordinasi, mual dan muntah. 10 


\section{KESIMPULAN}

Berdasarkan hasil dari penelitian ini, peneliti menyimpulkan bahwa persentase swamedikasi tertinggi adalah jenis analgesic $(96 \%)$ dan diikuti oleh jenis batuk/pilek (77\%). Dari semua kandungan yang digunakan banyak yang memiliki efek samping gangguan sistem gastrointestinal dan kantuk. Efek samping ini dapat menyebabkan penurunan konsentrasi pengemudi dan dapat menimbulkan kecelakaan lalu lintas yang dapat merugikan diri sendiri bahkan orang di sekitar.

\section{SARAN}

Berdasarkan kesimpulan penelitian, maka penulis merekomendasikan berupa saran-saran sebagai berikut :

1. Untuk meningkatkan pengetahuan dan informasi kepada para pelaku swamedikasi terutama pengemudi angkutan umum agar tidak terlalu sering mengkonsumsi obat-obatan tanpa resep dokter.

2. Diharapkan menambahkan informasi bagi petugas kesehatan dalam mengidentifikasi resiko yang mungkin terjadi akibat dari efek samping swamedikasi dari para pengemudi angkutan umum.

3. Untuk peneliti selanjutnya diharapkan dilakukan penyuluhan kesehatan agar pelaku swamedikasi dapat lebih bijak untuk bertindak.

\section{DAFTAR PUSTAKA}

Steven, Antonius, dan Yosi. (2018). Profil Swamedikasi Analgesik di
Masyarakat Surabaya, Jawa Timur. Jurnal Ilmu Kefarmasian Indonesia. 86-93.

Ana, Haafizah, dan Murtyk. (2017). Tingkat Pengetahuan Penggunaan Obat Bebas dan Obat Bebas Terbatas untuk Swamedikasi pada Masyarakat rw 8 Morobangun Jogotirto Berbah Sleman Yogyakarta. Jurnal Ilmiah Manuntung.

Kemenkes RI. (2013). Riset Kesehatan Dasar. Jakarta : Badan Penelitian dan Pengembangan Kesehatan

Susi, Yayi, dan Riswaka. (2007). Perilaku Pengobatan Sendiri yang Rasional pada Masyarakat.Berita Kedokteran Masyarakat.

Eka fitria, (2013). Upaya Pengobatan Sendiri Pada Balita dalam Era Cakupan Semesta Jaminan Kesehatan. Jurnal kesehatan Masyarakat Nasional Vol 8 No 5.

Sudibyo Supardi dan Andi Leny. (2010). Penggunaan Obat Tradisional Dalam Upaya Pengobatan Sendiri Di Indonesia (Analisis Data Susenas Tahun 2007). Buletin Peneliti kesehatan Vol 38 No 2.

Prof. Dr. Sudarwan Danim. (2003). Riset Keperawatan Sejarah dan Metodologi. Jakarta: Buku Kedokteran EGC. 52-53

Patricia Ann Dempsey dan Arthur D. Dempsey. (2002). Riset Keperawatan Buku Ajar \& Latihan 
Edisi 4. Jakarta : Buku Kedokteran EGC.

Mims Petunjuk Konsultasi Edisi 18. (2018). Jakarta : BIP Gramedia.

Ikatan apoteker Indonesia. (2019).

Informasi Spesialite Obat Indonesia. Jakarta : PT. ISFI Penerbitan.

Mims Petunjuk Konsultasi Edisi 16 (2016). Jakarta : BIP Gramedia.

Rialita, Gayatri dan Frenly. (2013). Analisis Kafein dalam Kopi Bubuk di Kota Manado Menggunakan Spektrofometri UV-VIS. Jurnal Ilmiah Farmasi Vol 02 No 04

Febri, Juniar, dan Asri. (2013). Kandungan Salisilat Bebas dalam Tablet Asetosal yang Beredar di Surabaya. Berkala Ilmiah Kimia Farmasi Vol 2 No 2.

Meriam, Adeanne, dan Gayatri. (2013). Profil Penyalahgunaan Obat Dekstrometofan pada Masyarakat di Kecamatan Tombariri Timur Kabupaten Minahasa. Jurnal Ilmiah Farmasi Vol 2 No 04.

Ridwan, Nurhikmah, dan Muhammad. (2016). Penyalahgunaan Obat Keras oleh Buruh Bangunan di Pergudangan Parangloe Indah Kota Makasar. Jurnal MKMI Vol 12 No 2. 